\title{
Capacidade combinatória em milho-pipoca por meio de dialelo circulante
}

\author{
Silvério de Paiva Freitas Júnior( ${ }^{(1)}$, Antonio Teixeira do Amaral Júnior ${ }^{(1)}$, Messias Gonzaga Pereira(1), \\ Cosme Damião Cruz $^{(2)}$ e Carlos Alberto Scapim ${ }^{(3)}$
}

\begin{abstract}
(1)Universidade Estadual do Norte Fluminense Darcy Ribeiro, Laboratório de Melhoramento Genético Vegetal, Av. Alberto Lamego, no 2.000, Parque Califórnia, CEP 28013-602 Campos dos Goytacazes, RJ. E-mail: silveriojr@uenf.br, amaralir@uenf.br, messias@uenf.br (2)Universidade Federal de Viçosa, Dep. de Biologia Geral, Bioagro, Av. P.H. Rolfs, s/no, CEP 36571-000 Viçosa, MG. E-mail: cdcruz@ufv.br (3)Universidade Estadual de Maringá, Dep. de Agronomia, Av. Colombo, no 5.790, CEP 87020-900 Maringá, PR. E-mail: ca-scapim@uol.com.br
\end{abstract}

Resumo - O objetivo deste trabalho foi gerar informações sobre a capacidade combinatória de dez genitores de milhopipoca, em cruzamentos no esquema de dialelo circulante em dois ambientes, para futura utilização em programa de melhoramento. Os híbridos, genitores e testemunhas foram avaliados quanto à altura de plantas (AP), produção de grãos (PG) e capacidade de expansão (CE), em delineamento em blocos ao acaso, com quatro repetições. A análise conjunta do dialelo revelou reduzido comportamento diferencial dos genótipos, com predominância dos efeitos aditivos apenas para CE. Os genitores UNB2U-C1, BRS Angela, UNB2U-C2 e Viçosa-UFV foram os indicados para melhoramento intrapopulacional, ao passo que os híbridos de interesse para seleção interpopulacional foram PR-Ervália x BRS Angela eUNB2U-C1 x BRS Angela.

Termos para indexação: Zea mays, híbridos, parâmetros genéticos.

\section{Combining ability in popcorn by circulant diallel}

\begin{abstract}
The objective of this work was to obtain combining ability information about ten genitors of popcorn, in a circulant diallel crossing in two environments, for using in future breeding programs. The hybrids, genitors and controls were evaluated for plant height (PH), grain yield (GY) and popping expansion (PE), in a randomized complete block design with four replications. The joint analysis of circulant diallel showed reduced differences on the performance of the genotypes. The additive effects were more important than non-additive effects only for the CE. Genitors UNB2U-C1, BRS Angela, UNB2U-C2 and Viçosa-UFV were indicated for the intrapopulation breeding, while superior hybrids for the interpopulation breeding were PR-Ervália x BRS Angela and UNB2U-C1 x BRS Angela.
\end{abstract}

Index terms: Zea mays, hybrids, genetic parameters.

\section{Introdução}

Os cruzamentos dialélicos são amplamente utilizados em quase todas as espécies cultivadas, em razão do grande número de informações genéticas, que podem oferecer como inferências sobre a capacidade combinatória de genitores e híbridos (Cruz \& Regazzi, 2004). Em relação ao milho-pipoca, sua adoção no Brasil é recente, seja na avaliação de genitores para a formação de compostos ou mesmo para a seleção de híbridos com expressiva heterose (Scapim et al., 2002).

Nos últimos cinco anos, o mercado nacional de milhopipoca passou por mudanças, sobretudo no que se refere à relação de parceria entre produtores e empacotadoras, com reflexo na importação do produto. Até o início do ano agrícola 2003-2004, das 80 mil toneladas de milhopipoca consumidas anualmente no Brasil, 75\% correspondiam a grãos importados, principalmente da Argentina (Galvão et al., 2000). Na safra 2004-2005, segundo informações das empresas empacotadoras, foram importadas apenas cerca de 20 mil toneladas, em razão da importação de sementes de híbridos americanos registrados pela Yoki e utilização, em maior escala, de sementes híbridas de cultivares nacionais como IAC-112, desenvolvida pelo Instituto Agronômico, Campinas, SP, e Zélia, da Sementes Pioneer (Sawazaki, 2001).

O mercado de milho-pipoca, no País, ainda é incipiente, apesar da importância da cultura, em nível mundial (Pacheco et al., 1998; Galvão et al., 2000). A obtenção de variedade melhorada, a partir de 
composto definido por meio de análise dialélica, também é rara no Brasil, onde tem-se, por exemplo, a variedade melhorada BRS Angela, proveniente de ciclos de seleção recorrente no composto CMS-43, da Embrapa Milho e Sorgo (Pacheco et al., 2001).

A principal restrição aos cruzamentos dialélicos é o número de cruzamentos a serem efetuados, que se torna tarefa laboriosa, em razão do grande número de genitores. Uma opção que proporciona maior flexibilidade aos cruzamentos dialélicos, com relação ao número de genitores envolvidos, é o dialelo circulante. Esse método, proposto na década de 60, por Kempthorne \& Curnow (1961), embora possibilite o envolvimento de número maior de genitores, tem sido pouco utilizado, provavelmente em decorrência do ceticismo sobre a sua eficiência em relação aos dialelos completos.

Todavia, Veiga et al. (2000) compararam a eficiência dos dialelos circulantes com dialelos completos e constataram que os dialelos circulantes apresentam eficiência comparável à dos completos, na classificação dos pais, na estimação da capacidade geral de combinação (CGC) e na capacidade específica de combinação (CEC), bem como na magnitude das estimativas desses parâmetros. Mais recentemente, Ferreira et al. (2004) utilizaram dados de produção de espigas de um dialelo completo, de 28 populações de milho, e simularam as estimativas das capacidades combinatórias geral e específica, de dialelos circulantes com variação de 3 a 25 cruzamentos para cada genitor. Foram gerados mil dialelos circulantes e, de forma quase geral, as estimativas de CGC e CEC dos dialelos circulantes foram semelhantes às do dialelo completo.

Este trabalho teve como objetivo gerar informações sobre a capacidade combinatória de dez genitores de milho-pipoca, em esquema de dialelo circulante em dois ambientes, para utilização em programas de melhoramento.

\section{Material e Métodos}

As populações UNB2U-C1, UNB2U-C2, PR-Ervália, Viçosa-UENF, PA038-Maringá, Branco-Viçosa, ViçosaUFV, BRS Angela, Beija-Flor e SE013-Maringá foram selecionadas por apresentar grãos amarelos e brancos, porte baixo a médio e maior prolificidade em ensaios, implementados em Campos dos Goytacazes, RJ, com plantios em 23/5/2002 e 12/10/2002.
O algoritmo para estabelecimento dos cruzamentos do dialelo teve como base o proposto por Kempthorne \& Curnow (1961), tendo-se adotado o valor de s igual a 3 .

Para a obtenção dos híbridos, as dez populações a serem cruzadas foram cultivadas aos pares, em fileiras espaçadas em $1 \mathrm{~m}$, cada qual com $6 \mathrm{~m}$ de comprimento e com espaçamento entre plantas de $0,40 \mathrm{~m}$, em março de 2003, no Colégio Estadual Agrícola Antônio Sarlo, em Campos dos Goytacazes, RJ.

Os cruzamentos foram realizados manualmente entre as plantas dos pares de fileiras. Para tanto, realizou-se a cobertura dos pendões maduros de determinada planta de uma fileira, com saco de papel. Depois, o saco foi utilizado para encobrir espiga apta para polinização da planta da fileira-par correspondente. Foram realizadas polinizações de aproximadamente 100 espigas por par de fileira, para obtenção de quantidade suficiente de sementes para a continuidade do processo.

Os híbridos, genitores e testemunhas (UNB2U-C0, Viçosa, PR023-Maringá, Produtor-Maringá e IAC-112) foram semeados em novembro de 2003, em delineamento em blocos ao acaso, com quatro repetições, em dois ambientes contrastantes, no Estado do Rio de Janeiro: Campos dos Goytacazes, região norte, a $21^{\circ} 45^{\prime} \mathrm{S}$ e $41^{\circ} 20^{\prime} \mathrm{W}$, com $10 \mathrm{~m}$ de altitude, a $12 \mathrm{~km}$ da Uenf, com predominância de Argissolo Amarelo e clima tropical úmido, com verão chuvoso, inverno seco e temperatura do mês mais frio superior a $18^{\circ} \mathrm{C}$; e Itaocara, região noroeste, a $21^{\circ} 39^{\prime} \mathrm{S}$ e $42^{\circ} 05^{\prime} \mathrm{W}$, com $70 \mathrm{~m}$ de altitude, a $120 \mathrm{~km}$ da Uenf, com predominância de solo aluvial e clima tropical chuvoso de savana, com pequeno período seco. A parcela experimental foi constituída por uma fileira de $10 \mathrm{~m}$, espaçada de $1 \mathrm{~m}$ entre linhas e por 0,20 m entre plantas.

As seguintes características foram avaliadas: altura de plantas (AP), em cm; produção de grãos (PG), em kg ha-1; e capacidade de expansão dos grãos (CE), em $\mathrm{mL} \mathrm{g}^{-1}$. A capacidade de expansão dos grãos foi determinada em laboratório, pelo método recomendado por Pacheco et al. (1998), com pipoqueira elétrica da Embrapa Instrumentação Agropecuária, à temperatura de $270^{\circ} \mathrm{C}$ e tempo de pipocamento de 2 min e $30 \mathrm{~s}$. Na estimação da CE, utilizou-se, para cada tratamento, duas amostras de $30 \mathrm{~g}$ de grãos selecionados para maior uniformidade, 
após debulha manual. Procedeu-se a determinação da umidade dos grãos. Para tanto, os grãos obtidos das colheitas foram inseridos em secador. Em seguida, por meio de termômetro de bulbo úmido, averiguouse o teor médio de água nos grãos, que foi quantificado por meio do método-padrão de estufa com circulação de ar $\left(105^{\circ} \mathrm{C}\right.$, com desvio-padrão de $3^{\circ} \mathrm{C}$ ) durante 24 horas, com cinco repetições, sem realizar tritura da amostra, de acordo com as regras de análise de sementes (Brasil, 1992).

Para a análise genético-estatística dos resultados, utilizou-se o programa Genes (Cruz, 2001), empregandose o modelo: $Y_{i j}=\mu+g_{i}+g_{j}+s_{i j}+\xi_{i j}$, em que: $Y_{i j}$ é a média da observação associada à combinação híbrida ij $(\mathrm{i} \neq \mathrm{j}$ ) ou ao i-ésimo genitor ( $\mathrm{i}=\mathrm{j}) ; \mu$ é a média geral; $g_{\mathrm{i}} \mathrm{e}$ $g_{j}$ são os efeitos fixos da capacidade geral de combinação; $\mathrm{S}_{\mathrm{ij}}$ é o efeito fixo da capacidade específica de combinação; e $\xi_{\mathrm{ijj}}$ é o erro experimental médio.

Nas análises individuais, os estimadores das médias dos quadrados dos efeitos para CGC e CEC, considerados fixos, foram, respectivamente: $\Phi_{\mathrm{gi}}=\frac{\mathrm{QMCGC}(\mathrm{p}-1)-\mathrm{QMR}}{\mathrm{bs}(\mathrm{p}+2)} \mathrm{e}$

$\Phi_{\text {si }}=\frac{\text { QMCEC }- \text { QMR }}{\mathrm{b}}$, em que: QMCGC é o quadrado médio da capacidade geral de combinação; QMCEC é o quadrado médio da capacidade específica de combinação; QMR é o quadrado médio do resíduo; b é o número de blocos; s é o número de cruzamentos por genitor; e p é o número de genitores.

Na análise conjunta, adotou-se também o modelo fixo, em que os componentes da capacidade combinatória geral $\left(\Phi_{\text {gia }}\right)$ e específica $\left(\Phi_{\text {sia }}\right)$ em interação com o ambiente, foram obtidos pelas expressões:
$\Phi_{\text {gia }}=\frac{\text { QMCGCxA }(p-1)-\text { QMR }}{\text { bs }(p+2)}$, em que: QMCGCxA é o quadrado médio da capacidade geral de combinação em interação com o ambiente;

$\Phi_{\text {sia }}=\frac{\text { QMCECxA - QMR }}{\mathrm{b}}$, em que: QMCECxA é o quadrado médio da capacidade específica de combinação em interação com o ambiente.

Nas análises de variância dialélica, tanto individual quanto conjunta, foram utilizados os respectivos quadrados médios dos resíduos e graus de liberdade das análises de variância com as testemunhas, para fins de maior rigor na obtenção da estatística $\mathrm{F}$ e conseqüente maior exatidão da averiguação da significância.

\section{Resultados e Discussão}

Os quadrados médios para a capacidade geral (CGC) e específica de combinação (CEC), em Campos dos Goytacazes, foram significativos pelo teste $\mathrm{F}$ a $1 \%$ de probabilidade, para quase todas as características, o que denota a existência de variabilidade, resultante da ação de efeitos aditivos e não-aditivos no controle da expressão gênica.

Houve predominância dos efeitos gênicos aditivos para CE (Tabela 1), o que está em consonância com os resultados obtidos por Doffing et al. (1991), Larish \& Brewbaker (1999), Pereira \& Amaral Júnior (2001) e Simon et al. (2004). A maior importância dos efeitos de dominância para PG corrobora os estudos de Pereira \& Amaral Júnior (2001), Viana \& Pina Matta (2003) e Simon et al. (2004).

Considerando-se a produção de grãos (PG) e capacidade de expansão (CE) como as principais características para o melhoramento da cultura, infere-

Tabela 1. Estimativas dos quadrados médios de genótipos de milho-pipoca (genitores e $\mathrm{F}_{1}$ ’s), das capacidades geral (CGC) e específica de combinação (CEC) e do resíduo, e média dos quadrados dos efeitos da capacidade combinatória para altura da planta (AP, em cm), produção de grão (PG, em kg ha-1) e capacidade de expansão (CE, em mL g-1), avaliadas em dialelo circulante, em Campos dos Goytacazes, RJ.

\begin{tabular}{lrccc}
\hline Fonte de variação & GL & \multicolumn{2}{c}{ Quadrados médios } \\
\cline { 3 - 5 } & & AP & PG & CE \\
\hline Genótipos & 24 & $228,94^{\text {ns }}$ & $260.252,56^{* *}$ & $70,36^{* *}$ \\
CGC & 9 & $213,60^{\text {ns }}$ & $439.847,05^{* *}$ & $38,58^{* *}$ \\
CEC & 15 & $238,15^{\text {ns }}$ & $152.495,86^{* *}$ & $29,43^{* *}$ \\
Resíduo & 87 & 309,47 & $46.178,68$ & 10,34 \\
\hline Médias dos quadrados dos efeitos & & & & \\
CGC & & 8,90 & $24.904,33$ & 8,16 \\
CEC & 41,77 & $27.779,53$ & 5,36 \\
\hline
\end{tabular}

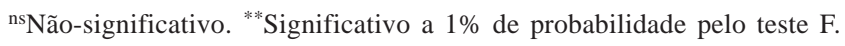


se que é possível a obtenção de ganhos para ambas as características, com a utilização de mesma estratégia de melhoramento, particularmente quando se empregam índices de seleção para a identificação das progênies superiores (Granate et al., 2002; Daros et al., 2004).

O genitor BRS Angela apresentou maior estimativa dos efeitos de CGC, para a característica CE, em Campos dos Goytacazes (Tabela 2). Quando se observam as médias dos híbridos, constata-se que o BRS Angela foi o genótipo que expressou as maiores magnitudes, em combinações com UNB2U-C1 e PR-Ervália, com valores respectivos de 23,40 e $24,27 \mathrm{~mL} \mathrm{~g}^{-1}$. Porém, pelas estimativas dos efeitos da CEC, as combinações com valores positivos para $\mathrm{CE}$ foram, hierarquicamente: PR-Ervália x Beija-Flor, UNB2U-C1 x Branco-Viçosa, PA038-Maringá x SE013-Maringá, PR-Ervália x UNB2U-C2, PA038-Maringá x UNB2U-C2 e PA038Maringá x Viçosa-UFV. Destas, as mais promissoras são UNB2U-C1 x Branco-Viçosa, PR-Ervália x BeijaFlor, PR-Ervália x UNB2U-C2, PA038-Maringá x UNB2U-C2 e PA038-Maringá $x$ Viçosa-UFV, já que pelo menos um dos genitores teve valor positivo e

Tabela 2. Estimativas dos efeitos da capacidade geral de combinação $\left(\hat{\mathrm{g}}_{\mathrm{i}}\right)$, da capacidade específica de combinação $\left(\hat{\mathrm{s}}_{\mathrm{ij}}\right)$, bem como das médias fenotípicas de três características, avaliadas em um dialelo circulante com dez genitores e 15 híbridos de milhopipoca, em Campos dos Goytacazes, $\mathrm{RJ}(1)$.

\begin{tabular}{|c|c|c|c|c|c|c|c|c|c|c|c|}
\hline \multirow[t]{7}{*}{ Genótipo } & \multirow[t]{2}{*}{ Característica } & \multicolumn{10}{|c|}{ Estimativas dos efeitos de $\hat{g}_{i}$} \\
\hline & & 1 & 2 & 3 & 4 & 5 & 6 & 7 & 8 & 9 & 10 \\
\hline & AP & 3,79 & $-5,49$ & 0,50 & $-0,24$ & $-3,48$ & $-1,92$ & 2,03 & $-0,14$ & 1,56 & 3,39 \\
\hline & PG & 207,54 & $-172,03$ & 10,56 & $-40,24$ & $-91,20$ & $-59,93$ & $-34,68$ & 189,63 & $-141,90$ & 132,26 \\
\hline & $\mathrm{CE}$ & 2,46 & $-0,30$ & $-3,21$ & $-2,55$ & $-1,39$ & 3,65 & 0,49 & 1,81 & $-1,34$ & 0,38 \\
\hline & & \multicolumn{10}{|c|}{$\begin{array}{l}\text { Estimativas dos valores de } \hat{\mathrm{s}}_{\mathrm{ij}} \text { (acima da diagonal), das médias fenotípicas dos genitores } \\
\text { (na diagonal) e dos híbridos (abaixo da diagonal) }\end{array}$} \\
\hline & & 1 & 2 & 3 & 4 & 5 & 6 & 7 & 8 & 9 & 10 \\
\hline \multirow[t]{3}{*}{1} & AP & 165,62 & & & & 2,49 & 8,08 & $-1,65$ & & & \\
\hline & PG & 997,50 & & & & $-42,69$ & 271,03 & 104,54 & & & \\
\hline & $\mathrm{CE}$ & 23,15 & & & & 2,18 & $-1,28$ & $-0,20$ & & & \\
\hline \multirow[t]{3}{*}{2} & AP & & 147,92 & & & & $-1,19$ & 7,96 & 0,39 & & \\
\hline & PG & & 221,25 & & & & 23,12 & 205,37 & 138,54 & & \\
\hline & $\mathrm{CE}$ & & 16,90 & & & & $-3,93$ & 5,39 & 0,65 & & \\
\hline \multirow[t]{3}{*}{3} & AP & & & 159,05 & & & & 3,06 & 1,13 & 4,69 & \\
\hline & PG & & & 763,75 & & & & $-73,47$ & 65,94 & 19,99 & \\
\hline & $\mathrm{CE}$ & & & 14,32 & & & & $-3,86$ & $-0,19$ & $-0,27$ & \\
\hline \multirow[t]{3}{*}{4} & AP & & & & 150,50 & & & & 7,52 & 9,78 & 5,73 \\
\hline & PG & & & & 472,50 & & & & 144,26 & 99,55 & 147,88 \\
\hline & $\mathrm{CE}$ & & & & 12,47 & & & & 0,14 & 1,73 & 0,08 \\
\hline \multirow[t]{3}{*}{5} & AP & 165,30 & & & & 148,87 & & & & 5,30 & 5,47 \\
\hline & PG & 822,50 & & & & 407,50 & & & & 343,01 & 17,58 \\
\hline & $\mathrm{CE}$ & 21,85 & & & & 17,35 & & & & $-4,01$ & $-1,24$ \\
\hline \multirow[t]{3}{*}{6} & AP & 172,45 & 167,00 & & & & 153,05 & & & & 4,52 \\
\hline & PG & 1167,50 & 747,50 & & & & 528,75 & & & & $-93,68$ \\
\hline & $\mathrm{CE}$ & 23,40 & 24,17 & & & & 28,97 & & & & $-0,96$ \\
\hline \multirow[t]{3}{*}{7} & AP & 166,67 & 155,62 & 168,10 & & & & 161,87 & & & \\
\hline & PG & 1026,25 & 526,25 & 651,25 & & & & 561,25 & & & \\
\hline & $\mathrm{CE}$ & 21,35 & 16,25 & 12,00 & & & & 18,90 & & & \\
\hline \multirow[t]{3}{*}{8} & AP & & 157,25 & 163,97 & 169,62 & & & & 157,67 & & \\
\hline & PG & & 905,00 & 1015,01 & 1042,50 & & & & 953,75 & & \\
\hline & $\mathrm{CE}$ & & 20,75 & 16,97 & 18,00 & & & & 21,92 & & \\
\hline \multirow[t]{3}{*}{9} & AP & & & 169,25 & 173,55 & 165,87 & & & & 155,75 & \\
\hline & PG & & & 637,50 & 666,25 & 858,75 & & & & 233,75 & \\
\hline & $\mathrm{CE}$ & & & 13,75 & 16,40 & 11,82 & & & & 17,17 & \\
\hline \multirow[t]{3}{*}{10} & AP & & & & 171,37 & 165,62 & 168,25 & & & & 161,52 \\
\hline & PG & & & & 988,75 & 775,00 & 727,50 & & & & 977,50 \\
\hline & $\mathrm{CE}$ & & & & 16,50 & 18,90 & 21,67 & & & & 20,40 \\
\hline
\end{tabular}

(1)AP: altura de plantas (cm); PG: produção de grãos (kg ha-1); CE: capacidade de expansão (mL g-1); 1: UNB2U-C1; 2: PR-Ervália; 3: Viçosa-UENF; 4: PA038-Maringá; 5: Branco-Viçosa; 6: BRS Angela; 7: Beija-Flor; 8: UNB2U-C2; 9: SE013-Maringá; 10: Viçosa-UFV. 
elevado para $\hat{\mathrm{g}}_{\mathrm{i}}$. Isto demonstra que o efeito desejável de acumulação gênica dos genitores UNB2U-C1 e PR-Ervália traduziu-se em efeito satisfatório de complementação gênica nas combinações. Vê-se, porém, que BRS Angela não está presente entre os pares mais promissores, o que se confirma pelo fato de as combinações UNB2U-C1 x BRS Angela e PR-Ervália x BRS Angela revelarem estimativas negativas dos efeitos de $\hat{s}_{\mathrm{ij}}$. Segundo Ferrão et al. (1985), tal situação decorre de elevada discrepância das estimativas de $\hat{g}_{i}$ e $\hat{g}_{j}$, o que pode resultar em estimativa baixa ou mesmo negativa de $\hat{s}_{\mathrm{ij}}$. Neste caso, recomenda-se a indicação do melhor híbrido com base na média; isto posto, para a presente situação, tem-se que os pares superiores foram: PR-Ervália x BRS Angela e UNB2U-C1 x BRS Angela.

Para a característica PG, apenas os genitores UNB2U-C1, UNB2U-C2, Viçosa-UFV e Viçosa-UENF apresentaram efeitos positivos de $\hat{g}_{i}$, em magnitudes decrescentes, nesta ordem, indicando que são genótipos de interesse para contribuir para aumentos da produção de grãos (Tabela 2). Efeitos positivos de CEC para PG estiveram presentes em quase todos os híbridos (Tabela 2). Entretanto, considerando-se que a melhor combinação deve ser aquela com maior valor de $\hat{s}_{\mathrm{ij}}$, cujos genitores apresentem alto valor de $\hat{g}_{\text {; }}$, destacaram-se como promissores os pares UNB2U-C1 x BRS Angela, PR-Ervália x UNB2U-C2, PA038-Maringá x UNB2U-C2 e PA038-Maringá x Viçosa-UFV, em que há pelo menos um genitor com valor de $\hat{\mathrm{g}}_{\mathrm{i}}$ elevado (Tabela 2).

Com base no conjunto de características avaliadas, conclui-se que os híbridos PR-Ervália x BRS Angela e UNB2U-C1 x BRS Angela destacaram-se dos demais, e que a combinação UNB2U-C1 x BRS Angela destacou-se, sobretudo para CE.

Os genitores UNB2U-C1, Viçosa-UFV e Beija-Flor apresentaram as estimativas positivas mais elevadas dos efeitos de CGC, para a característica altura de plantas (AP), em Campos dos Goytacazes (Tabela 2). Isso significa que esses genitores tendem a contribuir com o aumento da altura, nos programas em que participem, o que para Campos dos Goytacazes pode ser um problema, em razão dos ventos fortes que ocorrem na localidade. Porém, como a maior média fenotípica para AP foi de $165,62 \mathrm{~cm}$, verifica-se que as populações possuem altura adequada para serem utilizadas em futuros programas de melhoramento no norte fluminense.

Em Itaocara, os quadrados médios da CGC e CEC foram significativos a $1 \%$ de probabilidade pelo teste $\mathrm{F}$, para a maioria das características (Tabela 3), denotando a ocorrência de variabilidade aditiva e não-aditiva, o que remete à possibilidade de obtenção de novas variedades ou híbridos.

No ambiente de Itaocara, as estimativas das médias dos quadrados dos efeitos da CGC e CEC revelaram superioridade dos efeitos gênicos aditivos apenas para CE (Tabela 3). Portanto, há expectativa de maiores ganhos para CE em programas de seleção intrapopulacional. Para APe PG, maiores ganhos deverão ocorrer com estratégias interpopulacionais. Isto consubstancia os ganhos de 10,39\% para CE e 4,69\% para PG, preditos por Daros et al. (2002), em programa de seleção recorrente intrapopulacional, com famílias de irmãos completos, para a obtenção do ciclo C1 de UNB2U. Ganhos superiores para CE, em relação a PG, também foram preditos por Pacheco et al. (1998), na consecução do segundo ciclo de seleção recorrente entre

Tabela 3. Estimativas dos quadrados médios de genótipos de milho pipoca (genitores e $\mathrm{F}_{1}$ 's), das capacidades geral (CGC) e específica de combinação (CEC) e do resíduo, e média dos quadrados dos efeitos da capacidade combinatória para altura da planta (AP, em cm), produção de grão (PG, em kg ha ${ }^{-1}$ ) e capacidade de expansão (CE, em mL g-1), avaliadas em dialelo circulante, em Itaocara, RJ.

\begin{tabular}{lcccc}
\hline Fonte de variação & GL & \multicolumn{2}{c}{ Quadrados médios } \\
\cline { 3 - 5 } & & AP & $333.607,35^{* *}$ & CE \\
\hline Genótipos & 24 & $400,36^{* *}$ & $169.856,22^{\text {ns }}$ & $140,45^{* *}$ \\
CGC & 9 & $436,88^{* *}$ & $431.858,05^{* *}$ & $25,48^{* *}$ \\
CEC & 15 & $378,45^{* *}$ & $97.401,10$ & 7,54 \\
Resíduo & 87 & 215,72 & & \\
\hline Médias dos quadrados dos efeitos & & & $4.747,53$ & 8,30 \\
CGC & & 15,06 & $84.490,59$ & 4,56 \\
CEC & 45,63 & & \\
\hline
\end{tabular}

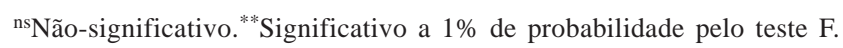


e dentro de famílias de meios-irmãos, nas populações CMS-42 e CMS-43.

Quanto à PG, os genitores UNB2U-C1, Viçosa-UENF, BRS Angela, UNB2U-C2 e SE013-Maringá apresentaram efeitos positivos para CGC, o que indica serem de interesse para aumento da produção. Com relação aos híbridos, apenas os pares UNB2U-C1 x Beija-Flor, PR-Ervália x UNB2U-C2 e Viçosa-UENF $\mathrm{x}$ Beija-Flor expressaram estimativas negativas de $\hat{\mathrm{s}}_{\mathrm{ij}}$. As maiores magnitudes positivas de $\hat{s}_{\mathrm{ij}}$ foram registradas por Viçosa-UENF x SE013-Maringá, PR-Ervália x Beija-Flor, PA038-Maringá x UNB2U-C2, UNB2U-C1 x BRS Angela, Branco-Viçosa x SE013-Maringá e BRS Angela x Viçosa-UFV (Tabela 4). Entre estes, destacaram-se Viçosa-UENF x SE013-Maringá, PA038-Maringá x UNB2U-C2, Branco-Viçosa x SE013-Maringá, UNB2U-C1 x BRS Angela e BRS Angela x Viçosa-UFV, por apresentar pelo menos um genitor com elevado valor positivo para a estimativa de $\hat{g}_{\mathrm{i}}$. Porém, segundo Ferrão et al. (1985),

Tabela 4. Estimativas dos efeitos da capacidade geral de combinação $\left(\hat{\mathrm{g}}_{\mathrm{i}}\right)$, da capacidade específica de combinação $\left(\hat{\mathrm{s}}_{\mathrm{ij}}\right)$, bem como das médias fenotípicas de três características, avaliadas em um dialelo circulante com dez genitores e 15 híbridos de milho-pipoca, em Itaocara, $\mathrm{RJ}{ }^{(1)}$.

\begin{tabular}{|c|c|c|c|c|c|c|c|c|c|c|c|}
\hline \multirow[t]{7}{*}{ Genótipo } & \multirow[t]{2}{*}{ Característica } & \multicolumn{10}{|c|}{ Estimativas dos efeitos de $\hat{\mathrm{g}}_{\mathrm{i}}$} \\
\hline & & 1 & 2 & 3 & 4 & 5 & 6 & 7 & 8 & 9 & 10 \\
\hline & AP & 2,34 & $-7,67$ & 2,47 & 1,48 & $-2,24$ & 2,52 & $-0,97$ & $-4,24$ & 5,83 & 0,47 \\
\hline & PG & 5,53 & $-102,74$ & 116,13 & $-27,51$ & $-110,85$ & 13,46 & $-49,59$ & 98,33 & 76,28 & $-19,04$ \\
\hline & $\mathrm{CE}$ & 1,11 & $-0,40$ & $-1,58$ & $-2,59$ & $-1,16$ & 4,90 & 0,39 & 1,83 & $-2,02$ & $-0,45$ \\
\hline & & \multicolumn{10}{|c|}{$\begin{array}{l}\text { Estimativas dos valores de } \hat{\mathrm{s}}_{\mathrm{ij}} \text { (acima da diagonal), das médias fenotípicas } \\
\text { dos genitores (na diagonal) e dos híbridos (abaixo da diagonal) }\end{array}$} \\
\hline & & 1 & 2 & 3 & 4 & 5 & 6 & 7 & 8 & 9 & 10 \\
\hline \multirow[t]{3}{*}{1} & AP & 175,12 & & & & $-4,73$ & 9,86 & 8,49 & & & \\
\hline & PG & 826,25 & & & & 77,17 & 354,09 & $-57,83$ & & & \\
\hline & $\mathrm{CE}$ & 21,57 & & & & $-0,01$ & 0,89 & $-1,75$ & & & \\
\hline \multirow[t]{3}{*}{2} & AP & & 159,12 & & & & 2,38 & 8,38 & $-5,21$ & & \\
\hline & PG & & 565,00 & & & & 67,37 & 417,94 & $-22,49$ & & \\
\hline & $\mathrm{CE}$ & & 17,15 & & & & $-3,91$ & 6,35 & $-0,59$ & & \\
\hline \multirow[t]{3}{*}{3} & AP & & & 185,00 & & & & $-17,01$ & 4,75 & 6,67 & \\
\hline & PG & & & 983,75 & & & & $-57,19$ & 29,87 & 528,17 & \\
\hline & $\mathrm{CE}$ & & & 17,42 & & & & $-1,88$ & $-0,58$ & $-0,87$ & \\
\hline \multirow[t]{3}{*}{4} & AP & & & & 167,37 & & & & 3,74 & 12,54 & 9,40 \\
\hline & PG & & & & 665,00 & & & & 404,77 & 125,57 & 33,40 \\
\hline & $\mathrm{CE}$ & & & & 14,82 & & & & 0,17 & 0,21 & $-2,60$ \\
\hline \multirow[t]{3}{*}{5} & AP & 172,62 & & & & 173,37 & & & & $-0,85$ & 4,38 \\
\hline & PG & 973,75 & & & & 558,75 & & & & 267,67 & 98,00 \\
\hline & $\mathrm{CE}$ & 18,85 & & & & 18,00 & & & & $-2,46$ & $-0,36$ \\
\hline \multirow[t]{3}{*}{6} & AP & 192,00 & 177,00 & & & & 182,75 & & & & $-13,13$ \\
\hline & PG & 1375,00 & 1267,50 & & & & 697,50 & & & & 241,18 \\
\hline & $\mathrm{CE}$ & 25,82 & 25,25 & & & & 29,00 & & & & 2,46 \\
\hline \multirow[t]{3}{*}{7} & AP & 187,12 & 174,50 & 161,75 & & & & 175,37 & & & \\
\hline & PG & 900,00 & 980,00 & 1011,25 & & & & 751,25 & & & \\
\hline & $\mathrm{CE}$ & 18,67 & 19,50 & 15,82 & & & & 18,35 & & & \\
\hline \multirow[t]{3}{*}{8} & AP & & 160,12 & 180,25 & 178,25 & & & & 167,12 & & \\
\hline & PG & & 975,00 & 1246,25 & 1477,50 & & & & 992,50 & & \\
\hline & $\mathrm{CE}$ & & 19,75 & 18,57 & 18,32 & & & & 23,10 & & \\
\hline \multirow[t]{3}{*}{9} & AP & & & 192,25 & 197,12 & 180,00 & & & & 179,75 & \\
\hline & PG & & & 1722,50 & 1176,25 & 1235,00 & & & & 693,75 & \\
\hline & $\mathrm{CE}$ & & & 14,42 & 14,50 & 13,25 & & & & 16,42 & \\
\hline \multirow[t]{3}{*}{10} & $\mathrm{AP}$ & & & & 188,62 & 179,87 & 167,12 & & & & 177,87 \\
\hline & PG & & & & 988,75 & 970,00 & 1237,50 & & & & 777,50 \\
\hline & $\mathrm{CE}$ & & & & 13,27 & 16,90 & 25,82 & & & & 18,22 \\
\hline
\end{tabular}

(1)AP: altura de plantas (cm); PG: produção de grãos (kg ha-1); CE: capacidade de expansão (mL g-1); 1: UNB2U-C1; 2: PR-Ervália; 3: Viçosa-UENF; 4: PA038-Maringá; 5: Branco-Viçosa; 6: BRS Angela; 7: Beija-Flor; 8: UNB2U-C2; 9: SE013-Maringá; 10: Viçosa-UFV. 
os desvios entre $\hat{g}_{i}$ e $\hat{g}_{j}$ foram suficientemente discrepantes, para expressar valor baixo de $\hat{s}_{\mathrm{ij}}$ para PR-Ervália x BRS Angela e, conseqüentemente, não destacar esse híbrido, que deteve a quarta maior média $\left(1.267,50 \mathrm{~kg} \mathrm{ha}^{-1}\right)$ entre as combinações. Por conseguinte, as combinações são indicadas com base nas médias e, por essas inferências, sobressaíram-se Viçosa-UENF x SE013-Maringá, PA038-Maringá x UNB2U-C2, UNB2U-C1 x BRS Angela, e PR-Ervália x BRS Angela.

Para a característica AP, no que se refere à CGC (Tabela 4), os genitores com maiores estimativas de $\hat{g}_{i}$ negativas (PR-Ervália, UNB2U-C2 e Branco-Viçosa) constituem materiais importantes, para serem incluídos em programas de melhoramento com propósitos de redução do porte da planta, já que a maior média para AP, entre genitores e híbridos em Campos dos Goytacazes, foi de 1,65 m; em Itaocara, houve expressão de magnitude próxima a 1,90 m, o que é inconveniente, em decorrência dos fortes ventos que também ocorrem no noroeste fluminense.

Com relação à característica $\mathrm{CE}$, destacaram-se BRS Angela, UNB2U-C2 e UNB2U-C1, por apresentar as magnitudes mais elevadas de $\hat{g}_{i}$; por conseguinte, são genótipos promissores para obtenção de populações com maior expressividade para a capacidade de expansão (Tabela 4). Os maiores valores de $\hat{s}_{\mathrm{ij}}$ para CE, em ordem decrescente, foram manifestados nos híbridos PR-Ervália x Beija-Flor,
BRS Angela x Viçosa-UFV, UNB2U-C1 x BRS Angela, PA038-Maringá x SE013-Maringá e PA038-Maringá x UNB2U-C2; contudo, as combinações mais promissoras são UNB2U-C1 x BRS Angela, PA038-Maringá x UNB2U-C2, PR-Ervália x Beija-Flor e BRS Angela $x$ Viçosa-UFV, por apresentar pelo menos um dos genitores com valor positivo de $\hat{\mathrm{g}}_{\mathrm{i}}$. Todavia, pela premissa de Ferrão et al. (1985), os melhores híbridos foram UNB2U-C1 x BRS Angela, PR-Ervália x BRS Angela e BRS Angela x Viçosa-UFV.

$\mathrm{O}$ conjunto de características avaliadas leva à conclusão de que as combinações UNB2U-C1 x BRS Angela, PR-Ervália x BRS Angela e BRS Angela $x$ Viçosa-UFV são as de melhor potencial, para utilização em programas de melhoramento, para obtenção de segregantes superiores, em Itaocara.

A análise conjunta dos quadrados médios dos efeitos dos genótipos, de ambientes, da interação GxA e seus desdobramentos (Tabela 5), demonstra que houve significância a $1 \%$ de probabilidade, pelo teste $\mathrm{F}$, entre os genótipos, para as principais características de interesse para o melhoramento da espécie.

Pela elevada significância da GxA em relação a PG, pode-se inferir que tal resultado decorreu do efeito significativo, a 5\% de probabilidade pelo teste F, para a interação CGCxA, o que pressupõe que os genitores revelaram diferenciações superiores aos híbridos, nos ambientes avaliados. Porém, essa assertiva não é verdadeira, posto que a média dos quadrados dos efeitos

Tabela 5. Estimativas dos quadrados médios de genótipos de milho-pipoca (genitores e $\mathrm{F}_{1}$ 's), das capacidades geral (CGC) e específica de combinação (CEC) e do resíduo, e média dos quadrados dos efeitos da capacidade combinatória para altura da planta (AP, em cm), produção de grão (PG, em kg ha-1) e capacidade de expansão (CE, em mL g ${ }^{-1}$ ) avaliadas em Campos dos Goytacazes e Itaocara, RJ.

\begin{tabular}{lrrrr}
\hline Fonte de variação & GL & \multicolumn{2}{c}{ Quadrados médios } \\
\cline { 3 - 5 } & & AP & PG & CE \\
\hline Genótipo & 24 & $478,29^{* *}$ & $447.100,52^{* *}$ & $130,46^{* *}$ \\
CGC & 9 & $522,69^{* *}$ & $394.095,95^{* *}$ & $269,37^{* *}$ \\
CEC & 15 & $451,66^{* *}$ & $478.903,25^{* *}$ & $47,11^{* *}$ \\
Ambientes & 1 & $10.906,46^{* *}$ & $3.201 .715,12^{* *}$ & $5,30^{\text {ns }}$ \\
GxA & 24 & $151,01^{\text {ns }}$ & $146.759,39^{* *}$ & $8,36^{\text {ns }}$ \\
CGCxA & 9 & $127,79^{\text {ns }}$ & $215.607,31^{*}$ & $9,29^{\text {ns }}$ \\
CECxA & 15 & $164,94^{\text {ns }}$ & $105.450,64^{\mathrm{ns}}$ & $7,79^{\text {ns }}$ \\
Resíduo & 174 & 262,60 & $71.789,89$ & 8,94 \\
\hline Médias dos quadrados dos efeitos & & & & 8,18 \\
CGC & & 12,16 & $10.201,85$ & 4,94 \\
CEC & & 39,77 & $51.408,32$ & 0,10 \\
CGC & & $-0,35$ & $9.248,16$ & 0,05 \\
CEC & & 7,86 & $9.453,48$ & \\
\hline
\end{tabular}

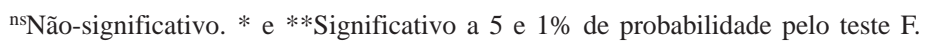


para CGC $_{\text {ga }}$ e CEC $_{\text {sa }}$ se equivaleram, com valores respectivos de 9.248,1638 e 9.453,4859 (Tabela 5).

Ainda, em relação a PG, esta foi a única característica que exibiu significância para a fonte de variação $G x A$, o que indica um reduzido comportamento diferencial dos genótipos nos ambientes para as demais características, o que é de fundamental importância no aproveitamento dos componentes do dialelo, em programas de melhoramento, em ambos os ambientes.

Com relação à performance das testemunhas, 0 híbrido IAC-112 revelou superioridade fenotípica para CE, com média $28,17 \mathrm{~mL} \mathrm{~g}^{-1}$ nos ensaios do presente trabalho. Todavia, na consecução de ensaios mais recentes (ano agrícola 2005-2006), houve aumento na estimativa de CE deste híbrido para $33,90 \mathrm{~mL} \mathrm{~g}^{-1}$ (Rangel, 2006). As populações UNB2U-C1, BRS Angela, UNB2U-C2 e Viçosa-UFV, que neste trabalho tiveram estimativas médias de CE de 22,36, 28,98, 22,51 e 19,31 $\mathrm{mL} \mathrm{g}^{-1}$, respectivamente (Tabelas 2 e 4), na avaliação no ano agrícola 2005-2006, tiveram essas médias elevadas para 24,40, 32,55, 25,37 e 20,54 $\mathrm{mL} \mathrm{g}^{-1}$, respectivamente (Rangel, 2006).

A maior expressão de CE provavelmente está relacionada a modificações no manejo da cultura, que passou a ser cultivada em fileiras duplas, tendo recebido dosagem mais elevada de adubação por ocasião do plantio, com irrigações periódicas. De qualquer forma, não se deve alijar a possibilidade de manifestação de efeitos adaptativos das populações nas regiões norte e noroeste fluminenses. Corrobora tal assertiva o fato de que o híbrido UNB2U-C1 x BRS Angela produziu, no presente trabalho, 1.271,25 $\mathrm{kg} \mathrm{ha}^{-1} \mathrm{e}$, no plantio de 2005-2006, $2.833,75 \mathrm{~kg} \mathrm{ha}^{-1}$, cujo valor é próximo de 50 sacas ha-1, que tem sido a produtividade média de determinadas regiões produtoras do país.

\section{Conclusões}

1. As combinações PR-Ervália x BRS Angela e UNB2U-C1 x BRS Angela são de interesse para obtenção de segregantes superiores.

2. Recomenda-se seleções intrapopulacionais no composto UNB2U-C1 e BRS Angela.

3. A análise de dialelo circulante, em um conjunto de ambientes, provê resultados mais adequados do que a avaliação em um único ambiente.

\section{Referências}

BRASIL. Ministério da Agricultura e Reforma Agrária. Comissão Técnica de Normas e Padrões. Normas de identidade, qualidade, embalagem e apresentação do milho. Brasília: Ministério da Agricultura e Reforma Agrária, 1992. 12p.

CRUZ, C.D. Programa Genes: versão Windows; aplicativo computacional em genética e estatística. Viçosa: Imprensa Universitária, 2001. 648p.

CRUZ, C.D.; REGAZZI, A.J. Modelos biométricos aplicados ao melhoramento genético. Viçosa: Imprensa Universitária, 2004. 390p.

DAROS, M.; AMARAL JÚNIOR, A.T. do; PEREIRA, M.G. Genetic gain for grain yield and popping expansion in full-sib recurrent selection in popcorn. Crop Breeding and Applied Biotechnology, v.2, p.339-344, 2002.

DAROS, M.; AMARAL JÚNIOR, A.T. do; PEREIRA, M.G.; SANTOS, F.S.; GABRIEL, A.P.C.; SCAPIM, C.A.; FREITAS JÚNIOR, S. de P.; SILVÉRIO, L. Recurrent selection in inbred popcorn families. Scientia Agricola, v.61, p.609-614, 2004.

DOFFING, S.M.; D’CROZ-MASON, N.; THOMAS-COMPTON, M.A. Inheritance of expansion volume and yield in two popcorn $\mathrm{x}$ dent corn crosses. Crop Science, v.31, p.715-718, 1991.

FERRÃO, R.G.; SILVA, J.C.; CRUZ, C.D. Avaliação da capacidade combinatória de oito linhagens de milho em um sistema dialélico desbalanceado. Revista Ceres, v.32, p.283-292, 1985.

FERREIRA, F.M.; RIBEIRO JÚNIOR, J.I.; PACHECO, C.A.P.; SILVA, C.H.O.; CRUZ, C.D. Efficiency of circulant diallels as compared to complete diallels for the estimation of general and specific combining ability. Crop Breeding and Applied Biotechnology, v.4, p.145-151, 2004.

GALVÃO, J.C.C.; SAWAZAKI, E.; MIRANDA, G.V. Comportamento de híbridos de milho pipoca em Coimbra, Minas Gerais. Revista Ceres, v.47, p.201-218, 2000.

GRANATE, M.J.; CRUZ, C.D.; PACHECO, C.A.P. Predição de ganho genético com diferentes índices de seleção no milho-pipoca CMS-43. Pesquisa Agropecuária Brasileira, v.37, p.1001-1008, 2002.

KEMPTHORNE, O.; CURNOW, R.N. The partial diallel cross. Biometrics, v.17, p.229-250, 1961.

LARISH, L.L.B.; BREWBAKER, J.L. Diallel analyses of temperate and tropical popcorns. Maydica, v.44, p.279-384, 1999.

PACHECO, C.A.P.; GAMA, E.P.; GUIMARÃES, P.E.O.; SANTOS, M.X.; FERREIRA, A.S. Estimativas de parâmetros genéticos nas populações CMS-42 e CMS-43 de milho-pipoca. Pesquisa Agropecuária Brasileira, v.33, p.1995-2001, 1998.

PACHECO, C.A.P.; GAMA, E.E.G.; PARENTONI, S.N.; SANTOS, M.S.; LOPES, M.A.; FERREIRA, A.S.; FERNANDES, F.T.; GUIMARÃES, P.E.O.; CORREA, L.A.; MEIRELLES, W.F.; FELDMAN, R.O.; MAGNAVACA, R. BRS Angela: variedade de milho-pipoca. Sete Lagoas: Embrapa Milho e Sorgo, 2001. 6p. (Comunicado técnico, 27).

PEREIRA, M.G.; AMARAL JÚNIOR, A.T. Estimation of genetic components in popcorn based on the nested design. Crop Breeding and Applied Biotechnology, v.1, p.3-10, 2001. 
RANGEL, R.M. Dialelo circulante na avaliação de híbridos e na identificação de compostos superiores de milho-pipoca. 2006. 134p. Dissertação (Mestrado) - Universidade Estadual do Norte Fluminense Darcy Ribeiro, Campos dos Goytacazes.

SAWAZAKI, E. A cultura do milho-pipoca no Brasil. O Agronômico, v.53, p.11-13, 2001.

SCAPIM, C.A.; PACHECO, C.A.P.; TONET, A.; BRACCINI, A.L.; PINTO, R.J.B. Análise dialélica e heterose de populações de milhopipoca. Bragantia, v.61, p.219-230, 2002.
SIMON, G.A.; SCAPIM, C.A.; PACHECO, C.A.P.; PINTO, R.J.B.; BRACCINI, A.L.; TONET, A. Depressão por endogamia em populações de milho-pipoca. Bragantia, v.63, p.55-62, 2004.

VEIGA, R.D.; FERREIRA, D.F.; RAMALHO, M.A.P. Eficiência dos dialelos circulantes na escolha de genitores. Pesquisa Agropecuária Brasileira, v.35, p.1395-1406, 2000.

VIANA, J.M.S.; PINA MATTA, F. de. Analysis of general and specific combining abilities of popcorn populations, including selfed parents. Genetics and Molecular Biology, v.26, p.465-471, 2003.

Recebido em 5 de setembro de 2005 e aprovado em 8 de agosto de 2006 